\title{
Group effects in urban shallow geothermal energy
}

\author{
Jean de Sauvage ${ }^{1, *}$, Bruno Regnicoli Benitez ${ }^{2}$, Fabien Szymkiewicz ${ }^{1}$ and Thibault Badinier ${ }^{1}$ \\ ${ }^{1}$ Université Gustave Eiffel, IFSTTAR, GERS Department, F-77447 Marne-la-Vallée, France \\ ${ }^{2}$ Università degli Studi di Perugia, DCEE, Italy
}

\begin{abstract}
Since the 1980 's, shallow geothermal solutions have been developed whose principle is to attach heat exchange pipes to the reinforcing cages of geotechnical structures. These low energy solutions combining a structural and a thermal role allow the fulfilling of the heating and cooling needs of buildings for a very low carbon cost. Energy geostructures are often placed in a groundwater flow. On one hand, it is a good way to avoid any multiyear thermal shift since the heat excess or default is tempered through the advection. This advection creates a thermal plume and heat waves in the soil can interact with downstream structures whose behaviour can be affected. The understanding of these interactions is essential for a smart management of the shallow geothermal development at the city scale. To study these interactions, a group of nine energy piles has been studied in Sense City, a mini city where a specific climate can be imposed and the underground water flow can be controlled. A numerical hydraulic-thermal coupled model was developed with the FEM software CESAR-LCPC to extrapolate the results. The combination of experimental and numerical models provides helpful results for the definition of guidelines concerning the prevention of interactions.
\end{abstract}

\section{Introduction}

The increasing energy needs in urban areas as well as the environmental imperatives have led the international research community and industry to develop new power supply technologies. Thus new geothermal solutions have been developed since the 1980s. Among them are energy geostructures, such as energy piles or energy diaphragm walls. The idea is to fix heat exchanger tubes to the reinforcement cages of those geotechnical structures $[1,2,3,4]$. This low enthalpy technology allows to produce both building heating and cooling for a low carbon cost, as it combines structural and thermal roles of underground structures.

Thermal geostructures are commonly interacting with the surrounding groundwater flow $[5,6]$. Advection along the flow can then regulate the potential multi-year temperature drift of the ground due to an excess heating or cooling [7, 8, 9, 10]. Nevertheless, this advection produces a thermal plume and heat waves in the ground which may interact with downstream geostructures, impacting their thermal behaviour and surrounding groundwater flow velocity profiles $[11,12]$. The thermomechanical behaviour of a single energy geostructure has been characterized through many research works but interactions between neighbouring geostructures have yet to be studied. This knowledge is critical to manage wisely those geothermal solutions at a district or city scale [13].

The scope of the following work is to provide physical modelling and simulation tools necessary to this kind of study. It focuses on the example of nine thermoactive piles, in an aquifer flow. This design has first been studied through physical modelling in the Sense-City test platform. A numerical simulation has then been conducted with the finite elements software CESARLCPC. This simulation features thermal and hydrological phenomena as well as their coupling.

\section{Physical modelling}

Sense-city is a $400 \mathrm{~m}^{2}$ test platform dedicated to the study of numerous physical phenomena involved in urban design and renewal. This platform is inside a climate chamber which allows tuning temperature, humidity and light levels. Sense-city features two construction sites where miniature cities can be erected inside the climate chamber to model the studied urban scenarios.

\subsection{Experimental layout}

The first mini-city scenario displays a geothermal installation with thermoactive geostructures. Three boxes, diaphragm-walled, and a group of nine micropiles ( $2 \mathrm{~m}$ long, $20 \mathrm{~cm}$ diameter and $80 \mathrm{~cm}$ between axes, equipped with HDPE tubes) are connected to a heat pump which can sollicit each of these structures independently (Figure 1). This mini-city is installed in a watertight pit to control the geotechnical conditions, such as the presence of groundwater and depth of the

\footnotetext{
* Corresponding author: jean.de-sauvage@ifsttar.fr
} 
water table. This pit is equipped with a pump able to impose a groundwater flow. Under the vegetal topsoil $(50 \mathrm{~cm})$, the main layer is a sandy soil (porosity $0.4, \mathrm{~d}_{50}$ $=2 \mathrm{~mm}$ ) whose permeability is about $10^{-4} \mathrm{~m} \cdot \mathrm{s}^{-1}$ and thermal conductivity is $1.8 \mathrm{~W} \cdot \mathrm{m}^{-1} \cdot \mathrm{K}^{-1}$.

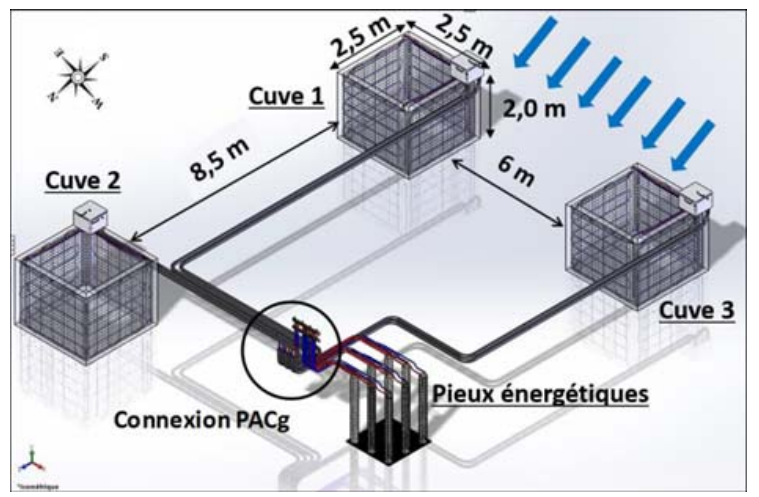

Fig. 1. Layout of the energy geostructures in Sense-City (credits : Univ Gustave Eiffel - IFSTTAR).

A network of optical fibres is installed in various spots, notably in the group of piles, in order to measure the temperature evolution throughout the experiment, all along the optical fibres, thanks to a Brillouin fibre interrogator. Its $3 \mathrm{D}$ layout can be visualized on Figure 2.b.

The following experiment consists in a serie of various thermal loadings aiming to heat the main building rooms with the help of the geothermal system. The heat pump programmer is used to control the system operating cycles. It was activated daily for a 10 hours span. Five energy geostructures were activated during this experiment. The decision was made to activate four of the nine geothermal piles, according to the setting depicted on Figure 2.a. This setting was maintained constant for the whole experiment and it allows the observation of various interactions between the active geostructures exposed to a flow. Furthermore, one of the thermoactive boxes was activated to provide sufficient power throughout the experiment and avoid a system emergency stop.

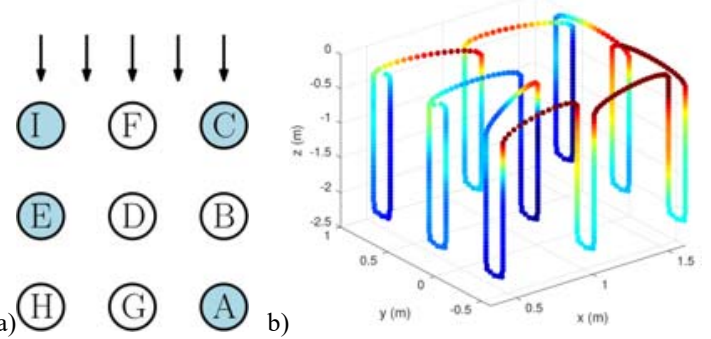

Fig. 2. a) Setting of the activated piles (in blue). b) 3D layout of the optic fibre in the piles.

A set of sensors was installed inside the climate chamber, in the building and in the circuit of the heat pump to follow the evolution of several thermal parameters. In particular, knowing the flow rate of the heat pump, the monitoring of the entry and exit temperatures of the heat transfer fluids allowed us to estimate the HP power during the operating phases to approximately $1120 \mathrm{~W}$. In the proposed setting, subtracting the estimated power of the additional diaphragm box, we estimate that the 4 geothermal piles power input only accounts for $560 \mathrm{~W}$. This estimation of $70 \mathrm{~W}$ per meter of pile is coherent with the literature [14].

During the experiment, the water table is set at a depth of $60 \mathrm{~cm}$, the piles are thus immersed over a height of $1.70 \mathrm{~m}$, and the pit pump is monitored to establish an average groundwater flow of $1.5 \mathrm{~m} . \mathrm{d}^{-1}$. Unfortunately the climate chamber failed to impose the ambient temperature during the whole experiment and the surface temperature can be observed on Figure 3. However the topsoil tends to temper the downward propagation of the thermal perturbations. A simple finite element simulation allowed us to guess the temperature fields at different depths. These values are presented on Figure 3 and are consistent with the soil temperature monitoring far away from the piles. The observed perturbations cannot be ignored but the frequency analysis carried out in this paper aims at overcoming this difficulty.

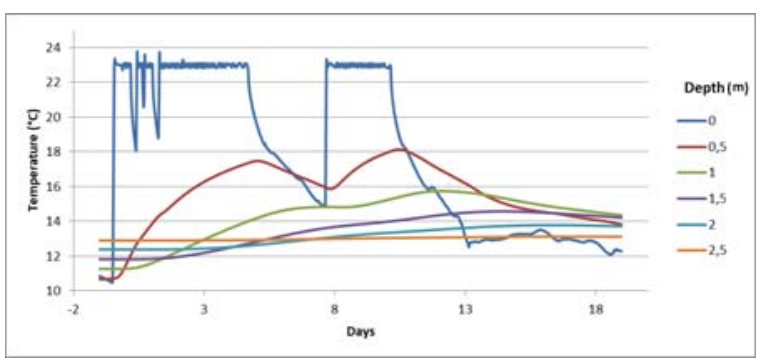

Fig. 3. Evolution of the ambient temperature during the experiment and the computed temperature values it induces at different depths. Day 0 is chosen as the beginning of the first heating cycle.

\subsection{Results}

The temperature measurements given by the optical fibre network is obtained from the measured excitation frequency of the optical fibre with a space resolution of one measure every $50 \mathrm{~mm}$ of fibre. Knowing the relation between the real 3D position of a measurement point and its position along the fibre, one can build a spatial representation of the temperature field (see Figure 2.b).

For example, on Figure 4, one can deduce the position of each pile along the fibre. At the start of the measurements, we observe a peak pattern. As the fibre is running up and down the piles, these temperature peaks are due to the vertical gradient in the soil and each one represents one pile. After 17 days, some peaks moved (the third, fifth, seventh and eighth) and other did not. It indicates the active piles. 


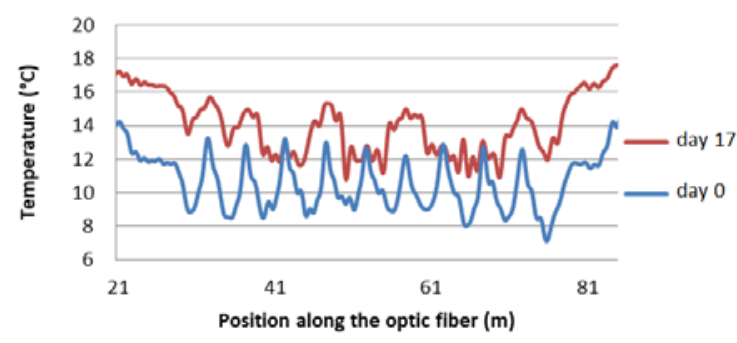

Fig. 4. Temperature measured along the fibre in the nine micropiles on the first day and after 17 days.

Figure 5 shows the evolution of the temperature through time in two points of the optic fibre. On an active pile, one can clearly observe the switching between the active and inactive phases of the heat pump. On an inactive pile, an influence is observed, however smoothened because of the diffusion process.

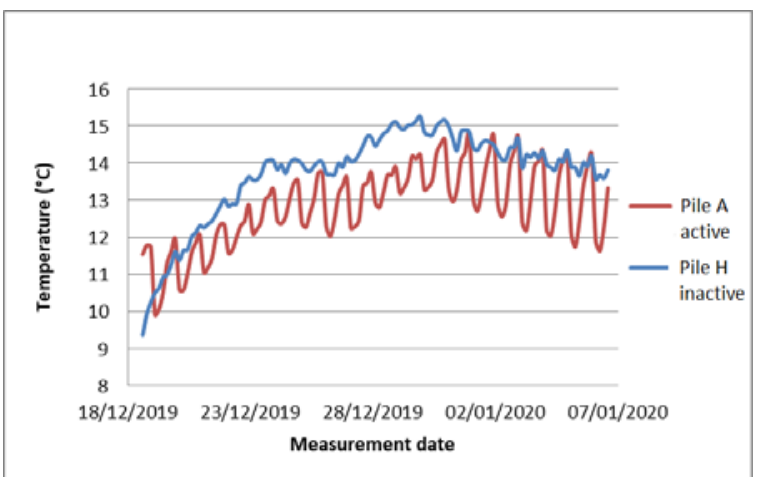

Fig. 5. Temperature measured over time on an active pile and an inactive one.

Figure 6 shows the evolution of temperature during time over the entire depth of a pile and reveals different phenomena. In particular, it can be observed that the variations of the ambient temperature propagate downwards in the soil, as mentioned in section 2.1. This observation is clearer on inactive piles (Figure 6.b). On the active pile (Figure 6.a), the daily heating and cooling cycles can be clearly observed through the apparition of vertical strips. A similar effect is observed with a smaller magnitude on adjacent inactive piles.

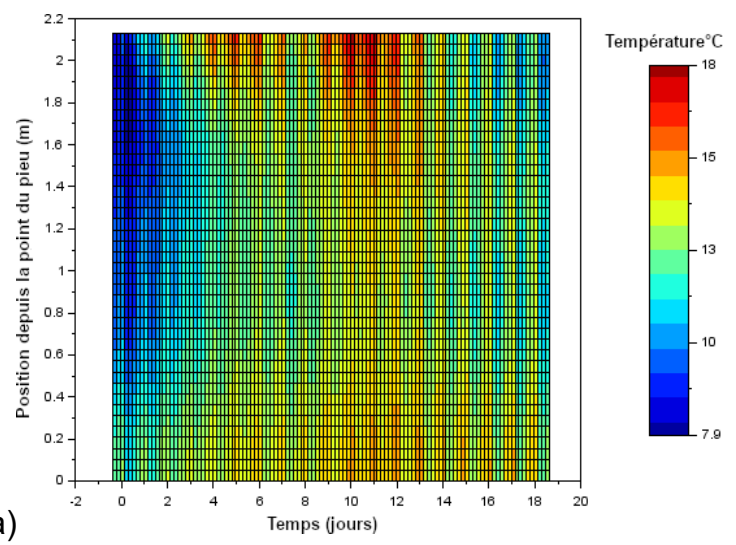

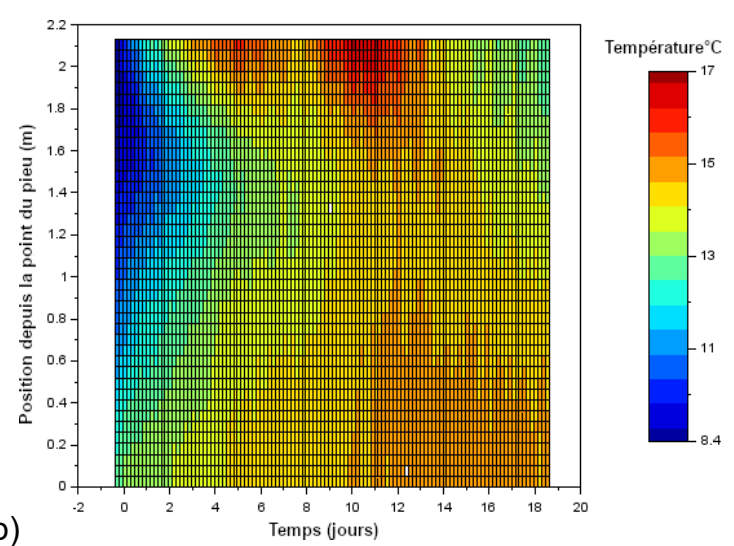

Fig. 6. Evolution of temperature during time over the entire depth of an active pile (a) and an inactive one (b).

A first simple analysis consists in the comparison of average pile temperatures, especially in the immersed part which is subjected to the advection phenomenon. It highlights the influence of one active pile on the downstream ones. Pile E, which is active and downstream of pile I, also active, is $0.47^{\circ} \mathrm{C}$ colder than pile $\mathrm{I}$ and $0.46^{\circ} \mathrm{C}$ than pile $\mathrm{C}$. I and $\mathrm{C}$ are active but not cooled down by any upstream geostructure. The same temperature difference is found again between piles B, upstream of one active pile, and $\mathrm{H}$, upstream of two active piles. It tends to indicate that the advection effects add up. Between $\mathrm{H}$ and $\mathrm{G}$, the temperature difference is $0.68^{\circ} \mathrm{C}$, showing the predominance of advection over conduction.

The experiment is subject to temperature evolutions on different timescales and the interaction between active and inactive piles is not easy to characterize. Therefore a frequency analysis has been carried out. The spectrum of the signals for different types of piles is presented on Figure 7. Note that all signals have a strong component for frequency $0.06 \mathrm{~d}^{-1}$. It is an artefact due to the sampling method. Pile E presents a major frequency at $1 \mathrm{~d}^{-1}$, corresponding to the heating and cooling cycles. Temperature of pile $\mathrm{H}$, which is located downstream of two activated piles, has also a strong daily component but its magnitude is smaller ( $40 \%$ of the daily magnitude of pile $\mathrm{E}$ ). Pile $\mathrm{D}$ is next to pile $\mathrm{E}$ but has no active upstream pile. The daily component of its temperature is very low, i.e. 5 times lower than on pile $\mathrm{H}$.

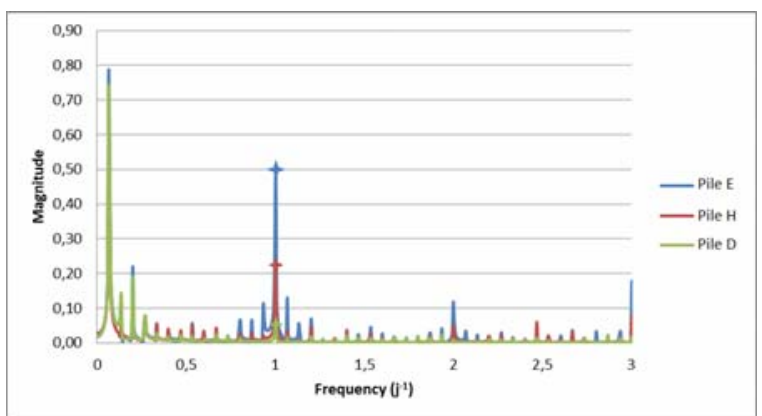

Fig. 7. Spectrum of temperature signals for piles $\mathrm{E}, \mathrm{H}$ and $\mathrm{D}$.

This ratio tends to indicate the predominance of advection over conduction. The Péclet number, which 
characterizes this competition [15] is here equal to 32 . The difference between these two ratios tends to indicate a distortion between theoretical and experimental results. However, it has to be noticed that the presence of piles disturbs the velocity field and pile D is not free from advective heat transfer.

\section{Numerical modelling}

The numerical modelling has been carried out using CESAR-LCPC. This finite element software has been designed by the LCPC (then IFSTTAR and now University Gustave Eiffel) to address civil engineering problems. Some modules allow the simulation of thermal and hydraulic phenomena.

\subsection{Tools and assumptions}

In an inert material with no internal energy production, temperature $T$ can be determined through the transient heat equation (1) where $C_{p}$ is the material volumetric heat capacity and $\mathbf{j}$ the heat flux in the material. When considering a coupled phenomenon of advection and conduction, the heat flux is the sum of the advection flux and of the diffusion one. The conduction one, $\mathbf{j}$, is given by the Fourier law (2) where $\lambda$ is the thermal conductivity of the material. The advection one, $\mathbf{j a}$, corresponds to the displacement of thermal energy due to the water velocity. It is computed with (3) where $\mathbf{v}$ is the Darcy velocity of the groundwater flow and $C_{w}$ the water volumetric heat capacity.

$$
\begin{gathered}
C_{p} \partial \mathrm{T} / \partial \mathrm{t}+\operatorname{div} \mathbf{j}=0 \\
\mathbf{j}_{\mathbf{c}}=-\lambda \operatorname{grad} \mathrm{T} \\
\mathbf{j}_{\mathbf{a}}=\mathbf{v} C_{w} \mathrm{~T}
\end{gathered}
$$

A transient thermal modelling taking into account these two types of heat flux can be realized with the DTNL module of CESAR-LCPC. In particular, its option VIT allows the computation of advection flux. At each step, the groundwater velocity field is first computed, taking into account the geostructures in a hydraulic model. This field is then used to compute the advection flux. Since only the influence of hydraulic phenomena on thermal ones is considered, this model is not fully coupled. However, for the situations considered, the influence of temperature on the fluid velocity, through a change in viscosity for example, can be neglected [7].

A 2D model was realised on a plane orthogonal to the pile direction (z-axis) and is shown on Figure 8. In order to temper the boundary effect, and especially in the flow direction, the dimensions were chosen to be $10 \mathrm{~m} \mathrm{x}$ $20 \mathrm{~m}$. The pile section is simplified and represented by a $20 \mathrm{~cm}$ diameter concrete disk with a $5 \mathrm{~cm}$ diameter heat exchange pipe in its center. The material parameters used are derived from [7].

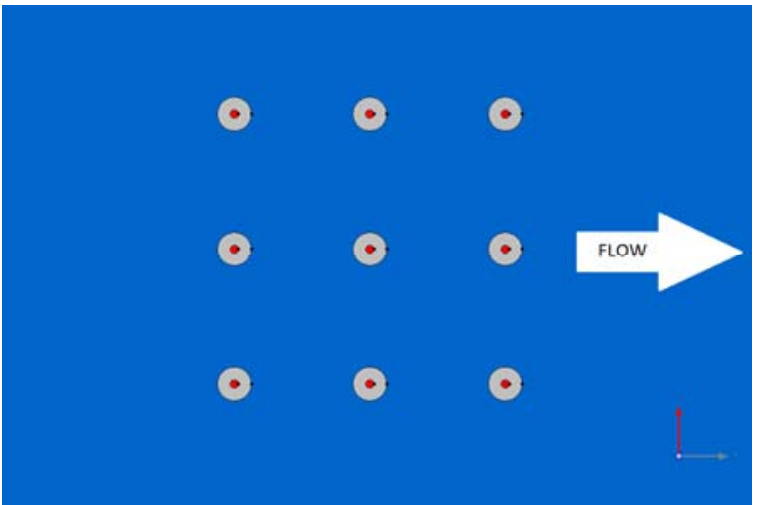

Fig. 8. Plane model of the pile group.

The global groundwater velocity is imposed by applying a pressure difference between upstream and downstream boundaries. The velocity field is visualized on Figure 9. To simulate a stable underground situation, the initial temperature is set to 13 degree $\mathrm{C}$ as well as the temperature on the boundaries during the whole experiment. On each active pile, a punctual power load of $-70 \mathrm{~W}$ is applied during ten hours a day. It is equivalent to the power extracted through one meter of pile according to the estimation made on section 2.1.

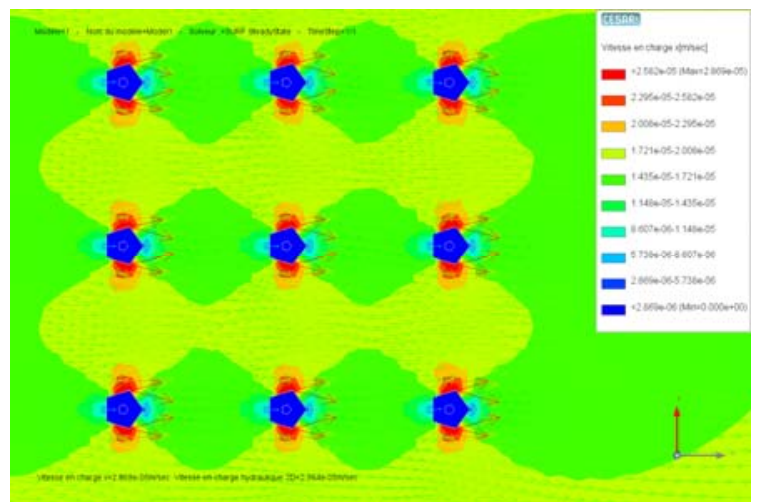

Fig. 9. Visualization of the computed groundwater velocity field.

\subsection{Results}

Six days are simulated with 30 min steps. The global behaviour in the neighbourhood of the piles is stabilized after 3 heating and cooling cycles and the thermal plume reaches the boundary during the fifth day. The final temperature field is visualized on Figure 10 where thermal plumes can be clearly observed downstream of the active piles. The plume displays the periodicity of the thermal loading as well as the impact of upstream active piles. 


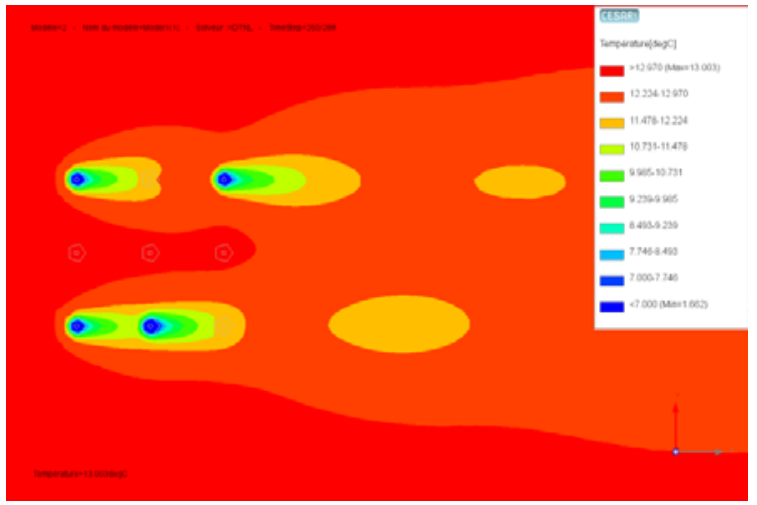

Fig. 10. Visualization of the computed final temperature field.

The evolution of pile temperatures is presented on Figure 11 and displays phenomena which are very similar to the ones observed on the physical model. The active piles $\mathrm{E}$ and I present a bigger daily temperature magnitude $\left(3-4^{\circ} \mathrm{C}\right)$ than the inactive ones impacted by the thermal plume $\left(1.4^{\circ} \mathrm{C}\right)$. This $40 \%$ ratio is consistent with the experimental observations. The piles not impacted by the plume present a smaller magnitude $\left(0.05^{\circ} \mathrm{C}\right.$ for the pile $\left.\mathrm{G}\right)$. It leads to a magnitude ratio of 27, quite similar to the Péclet number and the slight distortion observed in the physical modelling does not appear here.

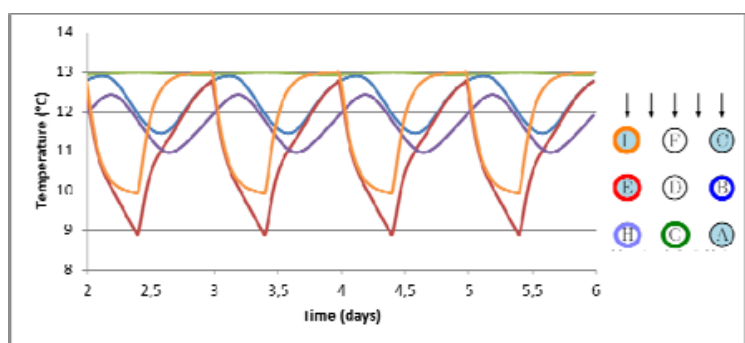

Fig. 11. Evolution of the computed temperature in each pile through time.

On average, the pile $\mathrm{H}$ is $0.75^{\circ} \mathrm{C}$ colder than another inactive one not impacted by the plume and $0.51^{\circ} \mathrm{C}$ colder than the pile $\mathrm{B}$. It confirms that the plume generated by a couple of piles induces a higher perturbation than the one generated by only one pile. The difference between $\mathrm{H}$ and $\mathrm{G}$ is equal to $1.23^{\circ} \mathrm{C}$. Even if these values are slightly higher than the one observed in the experiments they have the same order of magnitude and show the same principles.

In order to easily compare the numerical model and the experimental results, it was decided to define an impact index describing the influence of the heat pump activity on each pile. In the case of the experimental results, the impact index was taken as the magnitude of the daily component of the temperature signal. Concerning the numerical results, the impact index was defined as the thermal amplitude. To be able to compare both case, the impact indexes were normalised with the pile $I$ as a reference. These indexes are visualized on Figure 12.

Globally, numerical results and experimental data show a strong match and this bodes well for the predictive capacity of the finite-element model. However, we can notice that the numerical model overestimates the heat transfer along the flow and underestimate the transversal one. It is as if the Péclet number is a little higher in the numerical model than in the experiment.

The slight discrepancies between physical and numerical modelling can be attributed to the numerous parameters whose determination is uneasy in the field. For example, the knowledge of the real permeability map in Sense City is quite hard to get. Even if it would be a lot more time consuming, we can infer that $3 \mathrm{D}$ numerical simulations would provide more accurate results since they would take into account the effects of climate variations at the soil surface.

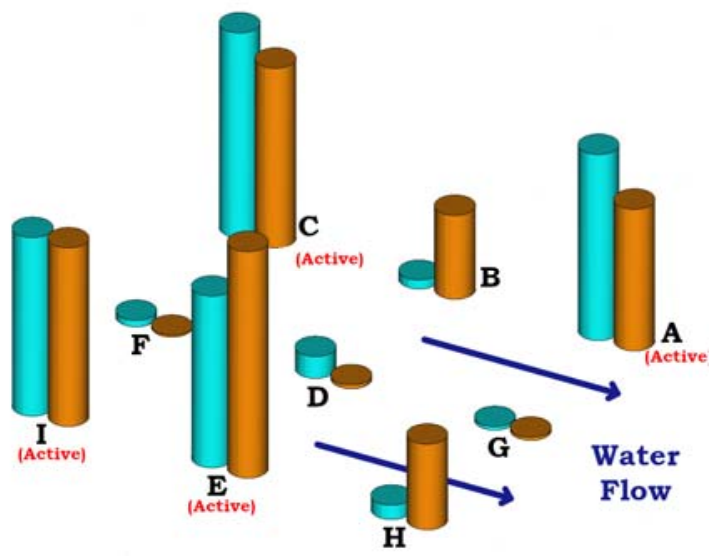

Fig. 11. Visualization of the impact index for each pile (blue: experimental data; orange : numerical results)

\section{Conclusions}

In this paper, the study of an energy pile group immersed in a groundwater flow and the interactions between theses piles due to the advection were presented. The physical and numerical modelling highlighted the same interaction phenomena and proved to be consistent with each other. They both give access to different pieces of information and their combination provides a useful tool for the further analysis of energy geostructures. The use of a frequency analysis allowed to get round the perturbations induced by surface temperature.

The influence of the upstream box and the consequences of variations in the flow velocity have still to be investigated. More case studies with a higher complexity have to be tested to pave the way for a smart management of shallow geothermal energy at the city scale.

The authors want to acknowledge the Sense-City team for providing access to this equipment. 


\section{References}

1. B.L. Amatya, K. Soga, P.J. Bourne-Webb, T. Amis, L. Laloui. Thermo-mechanical behaviour of energy piles. Géotechnique 62(6):503-19 (2012)

2. P.J. Bourne-Webb, S. Burlon, S. Javid, S. Kuerten, F. Loveridge. Analysis and design methods for energy geostructures. Renewable and sustainable energy 65:402-419 (2016)

3. T.Mimouni, L. Laloui. Behaviour of a group of energy piles. Canadian Geoechnical Journal 52(12):1913-14 (2015)

4. J.N. Franzius, N. Pralle. Turning segmental tunnels into sources of renewable energy. Proc. of the Institution of Civil Engineers-Civil Engineering 164(1):35-40 (2011)

5. G.P. Ding, J.J. Jiao, D.X. Zhang. Modelling study on the impact of deep building foundations on the groundwater system. Hydrol. Process 22(12), 18571865 (2008)

6. E. Pujades, A. Lopez, J. Carrera, E. Vázquez-Suñé, A. Jurado. Barrier effect of underground structures on aquifers. Eng. Geol. 145-146(7): 41-49 (2012)

7. Y. Delerablée. Intégration thermique et mécanique des géostructures thermiques : de l'échelle du bâtiment à l'échelle de la cite. $\mathrm{PhD}$ thesis. Univ. Paris-Est, Marne-la-Vallée (2019)

8. A. Fromentin, D. Pahud. Recommandations pour la realisation d'installations avec pieux échnageurs. Rapport final. Rapport d'étude $n^{\circ} 120.104$ Office fédéral de l'énergie, Lausanne, Suisse (1997)

9. D. Pahud, A. Fromentin, M. Hubbuch. Heat exchanger pile system of the dock midfield at the Zurich Airport. Detailed simulation and optimization of the installation. Rapport final. Rapport d'étude $n^{\circ} 120.110$. Office fédéral de l'énergie, Lausanne, Suisse (1999)

10. H. Brandl. Energy foundations and other thermoactive ground structures. Géotechnique 56(2): 81122

11. P. Eskilson. Thermal analysis of heat extraction boreholes. PhD Thesis. Lund University, Sweden (1987)

12. G. Radioti, B. Cerfontaine, R. Charlier, F. Nguyen. Experimental and numerical investigation of a longduration Thermal Response Test: Borehole heat exchanger behaviour and thermal plume in the heterogeneous rock mass. Geothermics, 71: 245-258 (2018)

13. M. Barla, A. Di Donna, M. Baralis. City-scale analysis of subsoil thermal conditions due to geothermal exploitation. Environmental Geotechnics 17(87), 11p (2018)

14. A. Di Donna, M. Barla, T. Amis. Energy Geostructures: Analysis from research and systems installed around the world. DFI $42^{\text {nd }}$ Annual Conference on Deep Foundations, New Orleans, USA (2017)
15. E. Guyon, L. Petit, J.P. Hulin. Hydrodynamique physique. Interéditions (1991) 